\title{
Alternative treatment options for periocular basal cell carcinoma: a narrative review
}

\author{
Kristina Erikson ${ }^{1}$, Anton Brosig ${ }^{1}$, Michael Walter Zimbelmann ${ }^{1}$, Steffen Emmert ${ }^{2}$, Yongwei Guo ${ }^{3,4}$, \\ Ludwig M. Heindl ${ }^{4,5}$, Irenäus A. Adamietz ${ }^{6}$, Mahdy Ranjbar ${ }^{1}$, Salvatore Grisanti ${ }^{1}$, Vinodh Kakkassery ${ }^{1}$ \\ ${ }^{1}$ Department of Ophthalmology, University of Lübeck, Lübeck, Germany; ${ }^{2}$ Clinic for Dermatology and Venereology, University Medical Center \\ Rostock, Rostock, Germany; ${ }^{3}$ Eye Center, Second Affiliated Hospital, School of Medicine, Zhejiang University, Hangzhou, China; ${ }^{4}$ Department of \\ Ophthalmology, University of Cologne, Faculty of Medicine and University Hospital Cologne, Cologne, Germany; ${ }^{5}$ Center for Integrated Oncology \\ (CIO) Aachen-Bonn-Cologne-Duesseldorf, Cologne, Germany; ${ }^{6}$ Department of Radiotherapy and Radio-Oncology, Ruhr-Universität Bochum, \\ Marien Hospital Herne, Herne, Germany \\ Contributions: (I) Conception and design: K Erikson, A Brosig, MW Zimbelmann, S Emmert, S Grisanti, V Kakkassery; (II) Administrative support: \\ LM Heindl, S Grisanti, V Kakkassery; (III) Provision of study materials or patients: All authors; (IV) Collection and assembly of data: K Erikson, A \\ Brosig, MW Zimbelmann, S Emmert; (V) Data analysis and interpretation: K Erikson, Y Guo, LM Heindl, M Ranjbar, S Grisanti, IA Adamietz, V \\ Kakkassery; (VI) Manuscript writing: All authors; (VII) Final approval of manuscript: All authors. \\ Correspondence to: PD Dr. med. Vinodh Kakkassery; Kristina Erikson. Klinik für Augenheilkunde, Universitätsklinikum Schleswig-Holstein, Campus \\ Lübeck, Universität zu Lübeck, Ratzeburger Allee 160, 23538 Lübeck, Germany. Email: vinodh.kakkassery@gmail.com; kristina.erikson@gmx.de.
}

Background and Objectives: Alternative treatment approaches to basal cell carcinoma (BCC) are necessary in inoperable BCC.

Methods: A summary was created based on an English and German literature searched on PubMed after 2010.

Key Content and Findings: This literature review presents the latest developments as well as established procedures that offer alternative treatment approaches to basal cell carcinoma when micrographically controlled surgical removal is not possible.

Conclusions: Micrographically controlled surgical removal remains the gold standard in the treatment of BCC. When surgical removal is impossible, other procedures can be chosen. The alternative treatment options can be divided into three main groups: treatment options for locally advanced or metastasized BCC, topical approaches for small and superficial BCC and prophylactic measures. While radiotherapy and systemic therapy are suitable for locally advanced BCC that are discussed in an interdisciplinary tumor board, small and superficial BCC can be treated by topical therapy. In cases of a previous BCC history, a prophylactic treatment can be considered. A combination of systemic treatment and neoadjuvant or adjuvant approaches before or after surgery are promising options for a successful outcome, which can further improve the standard treatment for locally advanced BCC. However, due to the lack of therapy success controls for both treatment options, almost all forms of therapy are inferior to micrographically controlled surgery and should therefore only be used if there are substantial reasons against R0 resection. In this review a literature search on PubMed was carried out and a structured display and analysis of the results are given.

Keywords: Treatment; basal cell carcinoma (BCC); radiation; hedgehog inhibitor; periocular

Received: 20 February 2021; Accepted: 22 July 2021; Published: 10 September 2022.

doi: $10.21037 /$ fomm-21-19

View this article at: https://dx.doi.org/10.21037/fomm-21-19 


\section{Introduction}

Eyelid basal cell carcinoma (BCC) is the most common human cancer to the eye, mostly located on the lower eyelid. It is a subtype of nonmelanoma skin cancer and its incidence is constantly increasing due to an aging population and widespread sun exposure. The eyelid is a particularly important part of the eye. It has two major functions, the protection of the globe and the secretion, distribution, and drainage of tears.

The gold standard for treatment of the eyelid BCC is a histologically controlled surgery with complete removal of the tumor. In some cases, there are fundamental reasons not to do surgery, e.g., in advanced BCC, metastatic disease, or recurrence. According to the German national guidelines, an advanced BCC is a tumor that needs an interdisciplinary therapy concept, due to anatomical difficulties regarding its extent and destructive growth. Also, sight reducing risks with surgery or patient wish are reasons not to do surgery and opt for alternative treatments. Limitations to surgical therapy could be the difficulty of eyelid reconstruction or the conservation of the bulb for tumors that reach closely. In rare cases also small BCC with low recurrence risk can profit from alternative treatment options $(1,2)$.

The alternative treatment options for BCC can be categorized into three treatment groups (Table 1): (I) systemor radiotherapy for locally advanced or metastasized BCC; (II) surgical or topical therapy for BCC $<2 \mathrm{~mm}$ tumor thickness and low risk of recurrence; (III) adjuvant prophylactic substances against recurrence for patients with BCC.

The first group are patients with locally advanced or metastasized BCC. An alternative way of treatment exists in radiation or system therapy. Different current national guidelines recommend to discuss the diagnosis within an interdisciplinary tumor board. Within a tumor board, the patient's individual results can be examined properly and a profound decision regarding the therapy option can be elaborated. A surgical option or a partly surgical option in combination with radiation or system therapy can be a suitable way to treat difficult cases. The final treatment option depends on the expertise of the caring clinic.

The second group consists of patients with BCC less than $2 \mathrm{~mm}$ tumor thickness and low risk of recurrence. Recurrence risk-enhancing factors include a horizontal tumor diameter of more than $6 \mathrm{~mm}$ in the periorbital area, a difficult-to-define limitation, a local recurrence, histological subtypes such as infiltrative, metatypical, or micro-nodular growth, tumor on irradiated skin as well as perineural growth. This group of patients with low risk of recurrence
Table 1 Overview of alternative treatment options for BCC

1. Alternative therapy for locally advanced BCC

- Hedgehog inhibitors

- Immune-Checkpoint-Inhibitors

- Electrochemotherapy

- Combination of different system therapies

- Radiotherapy

2. Alternative therapy for superficial, "low-risk" BCCs

- Photodynamic therapy with 5-ALA or MAL

- Imiquimod therapy

- 5-fluorouracil

- Semi-surgical procedures

- Laser therapy

- Electrodessication and curettage

- Cryotherapy

- Rhenium-188

- Diclofenac

3. Prophylaxis options

- Nicotinamide

- Retinoids

This table presents an overview of the alternative treatment options for BCC, based on the three categories "locally advanced BCC", "superficial, low risk BCC" and prophylaxis treatment options. BCC, basal cell carcinoma; 5-ALA, 5-aminolevulinic acid; MAL, methyl aminolevulinate.

are suitable for topical therapeutical options like imiquimod therapy (toll-like receptor 7 and 8 agonist), mitotic inhibitor 5-fluorouracil (5-FU), photodynamic therapy with 5-aminolevulinic acid (5-ALA) or methyl aminolevulinate (MAL), cryotherapy as well as laser therapy. Also, semisurgical treatment options like curettage or excision are part of the therapeutical concept of the small BCCs. Another topical therapy is a beta emitter isotope brachytherapy with Rhenium-188. There are existing promising studies with regards to clinical tumor remission and low side-effects by applying this radioactive paste directly on the tumor (3). Also, diclofenac, a nonsteroidal anti-inflammatory drug (NSAID), that can potentially interfere with the pathomechanism of BCC via inhibition of cyclooxygenase 2 (COX2). It is currently not recommended for the treatment of BCC due to the lack of evidence-based data. 
Table 2 The search strategy summary

\begin{tabular}{ll}
\hline Items & Specification \\
\hline Date of search & 18.2 .2021 \\
Databases and other sources searched & PubMed \\
Search terms used & Treatment, basal cell carci-noma, radiation, hedgehog inhibitor, periocular \\
Timeframe & After 2010 \\
Inclusion and exclusion criteria & Other language then English or Germany \\
Selection process & K Erikson, V Kakkassery, not independently discussion between both \\
\hline
\end{tabular}

In summary, topical procedures can be used in small BCCs with low risk of recurrence as an alternative to micrographically controlled surgery. Ultimately, however, the main criticism, in contrast to surgery, will always be the lack of success control that is provided by an $\mathrm{R} 0$ resection. Therefore, the authors almost always recommend offering surgery to patients in these cases, especially in the eye area.

The third group, the prophylactic options for patients with a history of BCC or high risk of recurrence, are being more or less recommended. Nicotinamide, a substance that enhances DNA (deoxyribonucleic acid) repair mechanisms, can be used in patients with BCC history, while retinoids, cell cycle inhibitors, have no significant effect in recurrence prophylaxis in BCC, but offer various side effects such as headaches, muscle pain and teratogenicity. As in the primary therapy of BCC, there is no evidence for the COX2 inhibitors in prophylaxis after an initial event $(3,4)$. We present the following article in accordance with the Narrative Review reporting checklist (available at https://fomm. amegroups.com/article/view/10.21037/fomm-21-19/rc).

\section{Methods}

A structured PubMed search of literature on alternative treatment options for BCC, with focus on eyelid BCC, was carried out for papers published until December 2020. The search strategy included the following key words: BCC, treatment, eyelid, periocular. For further detailed search on specific treatment options the key words were matched with the specific treatment (e.g., hedgehog, radiation, topical). Included were all studies within the past 15 years, since studies specifically for periocular BCC are rare for some treatments. However, $75 \%$ of the literature cited in this review has been published in the last 5 years between 2015 and 2020. Only English and German literature has been included (Table 2).

\section{Alternative treatment options}

\section{System therapy}

\section{Hedgehog-inhibitors}

An essential step in the pathogenesis of BCC is the described activation of the Hedgehog signaling pathway, which could be detected in over $90 \%$ of all these tumors. The Hedgehog signaling pathway regulates development, cell proliferation, and tissue repair (5) In clinical trials, the approved hedgehog inhibitors Vismodegib and Sonidegib achieved an overall response rate of greater than $50 \%$ and a median duration of response of $>24$ months (6).

Vismodegib (trade name Erivedge ${ }^{\circledR}$, Roche, Basel, Switzerland) has been approved for the indication of inoperable, non-beamable BCC or metastatic BCC based on the ERIVANCE study (Efficacy and Safety of Vismodegib in Advanced Basal Cell Carcinoma) https://www.ema. europa.eu/en). A total of 71 patients with inoperable, locally advanced findings and 33 patients with metastatic BCC were included in this study $(7,8)$. Patients with GorlinGoltz syndrome who were diagnosed with advanced BCC were also included. Patients were given $150 \mathrm{mg}$ of Vismodegib daily until either tumor progression occurred, medication led to toxic side effects, or the study was discontinued by the patient. In $30 \%$ of all patients with metastatic BCC and $60 \%$ of all patients with a locally pronounced finding, the tumor responded to the therapy. However, there were also significant side effects $(63 \%$ muscle spasms, $61 \%$ alopecia, $54 \%$ taste disorders, $32 \%$ weight loss, $28 \%$ asthenia, $22 \%$ loss of taste, $17 \%$ diarrhea, $16 \%$ fatigue, and $16 \%$ nausea) (9). These therefore explain to a large extent the high discontinuation rate of therapy. One-year data confirmed the positive treatment results as well as the significant side effects. Studies on Gorlin-Goltz syndrome have shown similar success (10). Further studies on the effect and safety of Vismodegib (STEVIE, NICCI 
and MIKIE study) showed comparable results (11). Women and men must use contraception measures during and after treatment due to the teratogenic effect of Hedgehog inhibitors. Since it is assumed that almost every BCC has a therapy-relevant Hedgehog pathway mutation, no discontinuation criteria were deliberately formulated in this chemotherapy. However, the attending physician should pay attention to whether the success of the therapy outweighs the side effects for the patient.

Sonidegib (trade name Odomzo ${ }^{\circledR}$, Sun Pharmaceutical, Mumbai, India) is indicated for the treatment of locally advanced BCC. It was approved on the basis of the BOLT study (Treatment with two different doses of Sonidegib in patients with locally advanced or metastatic BCC). Patients with non-treatable local BCC and metastatic BCC were treated with 200 and $800 \mathrm{mg}$ of Sonidegib respectively. Due to the more favorable benefit-to-risk profile with better response at the lower dose with $56 \%$ to $45 \%$ as well as less side effects, the approval for $200 \mathrm{mg}$ daily was therefore granted. It is contraindicated during pregnancy and breastfeeding, due to the important role of hedgehog pathway signaling in embryogenesis. It may lead to severe birth defects or fetal death (12). An application in metastatic cases is "off label" as this was not included in the indication area due to low response (13-16). Resistance to Vismodegib has been reported, although the incidence does not appear to be very high (e.g., $<10 \%$ in a study with 207 patients). Another study indicates, that patients who show a resistance to Vismodegib may also demonstrate a resistance to Sonidegib $(17,18)$. A critical point regarding the use of hedgehog inhibitors in general is the missing definition of success control. In micrographically controlled surgery the R0 resection is defined as success control, but for Vismodegib or others it is the clinical appearance, which could lead to wrongful conclusions. Although micrographically controlled surgery remains the treatment of choice in cases when surgical therapy is not possible Sonic hedgehog inhibitors are a good alternative. Current neoadjuvant approaches with Vismodegib prior to surgical excision could solve the issue of missing success control. In a case series of eight BCC patients, two patients had complete histological regression after a median duration of 6 months treatment with Vismodegib. The final surgical R0 excision showed no tumor recurrence after 13 months (19).

The use of Vismodegib in periocular BCC has been investigated in the STEVIE study. The patient's cohort consisted of 244 participants with periocular locally advanced basal cell carcinoma (POLA-BCC). The study showed that Vismodegib in periocular use showed a comparable side-effects profile than in non-ocular BCC (20). Another review conducted for the periocular treatment with Vismodegib reports a complete regression of $30 \%$ of patients, with follow-up less than 5 months. However, further randomized-controlled-trials are needed to investigate whether the use of Vismodegib in periocular BCC has an impact on local tumor control, survival, or quality of life (21). Figures 1,2 show periocular BCC before and after treatment with Vismodegib (22).

Furthermore, one of the key clinical questions regarding Sonidegib and Vismodegib focus around their relative riskbenefits and whether switching between the two substances is useful. In the absence of a head-to-head comparison study, the clinical relevance of pharmacokinetic profile of Sonidegib needs further studies to provide conclusive evidence (23). Currently there are new approaches for neoadjuvant use of Vismodegib in combination with surgery using microRNAs (miRNAs) sequencing. MicroRNA dysregulation has provided strong evidence for the participation in BCC development in recent studies. However, further studies are necessary (24).

\section{Immune-checkpoint-inhibitors}

The immune checkpoint inhibitors, especially the programmed cell death 1 (PD-1) antibody program, have almost revolutionized cancer treatment in the last 2 to 3 years. Initially, the value of PD-1 antibodies in small cell bronchial cell carcinoma could be demonstrated (25). Similar successes were also seen in cutaneous melanomas beyond treatment $(26,27)$.

The groundbreaking success of the immune checkpoint inhibitors is underlined by the award of the Nobel Prize in Medicine for their discovery in 2018. Immune checkpoints represent antigen barriers for the immune system and avoid detection of the body's own cells by immunocompetent cells. Cancer cells use this autoimmune protective function to remain undetected in front of the immune system. Immune checkpoint inhibitors override these antigen barriers so that immune-competent cells such as T-lymphocytes can detect and fight the tumor cell. This is particularly well done when there are particularly many tumor-related mutations in a cancer cell, as is the case with BCC. Various case reports have shown initial success of PD-1 antibodies in local or metastatic BCC (28-32). An approval study with the PD-1 antibody Cemiplimab in BCC is currently being conducted (REGN2810; NCT-No. 03132636), on whose data we look forward to. Here, too, an adjuvant or neoadjuvant use after 


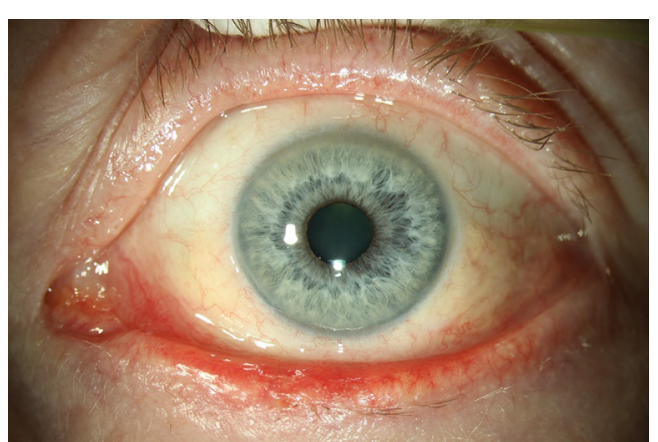

Figure 1 Treatment of periocular BCC with Vismodegib (22). This picture shows the left eye of a patient with lower eyelid BCC before treatment with Vismodegib. The tumor presented with marked blepharitis and ulcered lesion in the center of the lower eyelid margin with clinical suspicion of a morphea-type BCC. BCC, basal cell carcinoma.

or before surgical therapy can be exciting in the course of the periorbital area and in certain cases can also receive the eye in severe cases.

\section{Electrochemotherapy}

In electrochemotherapy, cell membranes for chemotherapy, mostly bleomycin, are temporarily permeable with nonthermal tumor ablation methods with electrical impulses. This approach is carried out in advanced tumors as well as in cutaneous metastases of different primaries (33-35). In this way, epithelial tumors such as BCC and in particular Gorlin-Goltz syndrome are treated (36,37). However, due to the low prevalence of this technique, there is hardly any reliable data for this treatment option.

\section{Combination of different system therapies}

New data and case reports on combined treatment concepts with a Hedgehog inhibitor and an immune checkpoint inhibitor are also eagerly awaited. It will be of interest whether the therapeutic successes add up and to what extent the side effect profile remains reasonable for the patient.

\section{Radiotherapy}

Radiotherapy is an alternative treatment option for invasive, inoperable BCC. It is recommended as definite as well as adjuvant therapy option in combination with surgery (35). Patient selection for radiation therapy is important and best done in a multidisciplinary setting. The major advantage of radiation therapy is that it generally provides a good

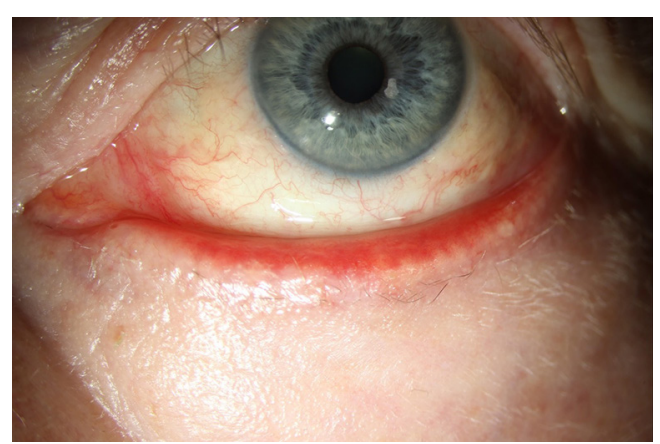

Figure 2 Treatment of periocular BCC with Vismodegib (22). This picture shows the left eye of a patient with periocular BCC after 6 months treatment with Vismodegib. There was marked persisting blepharitis and lower eyelid ectropion, suspicious for BCC recurrence. BCC, basal cell carcinoma.

result for tumors with extensive local destruction. Another reason to choose radiation over surgery could also be for recurrent tumors that have shown to be more aggressive and become progressively more difficult to treat with surgery. It might also be a suitable therapy option for patients who have contraindications for anesthesia and therefore cannot have an extensive surgical intervention as well as the desire for curative BCC treatment with organ preservation, bone infiltration or with a possible protection of the patient's physiognomy (38-40). Healing rates of the various forms of irradiation, fractional forms, conventional radiotherapy as well as brachytherapy, are comparable to conventional surgery. However, difficulties in assessing the skin for possible recurrences often exist due to scarring after irradiation.

Gorlin-Goltz syndrome is a relative contraindication to irradiation, as an increased secondary tumor rate or mass new BCCs were detected in the follow-up (41). Especially in the case of a residual tumor after the surgical excision of a BCC, the use of radiation therapy can be a useful option (42). The effectiveness of radiotherapy for aggressive BCCs was also demonstrated. A non-surgical treatment with definitive radiotherapy provides an effective alternative option if surgery is not performed (43).

Low dose-rate interstitial brachytherapy is a treatment that offers good local control and excellent cosmetic and functional results. As an alternative to surgery, brachytherapy can be used especially for small, Class T1-2 N0 carcinomas $(44,45)$.

In the context of radiation treatment, all these irradiation techniques are used accordingly. The goal is to achieve 


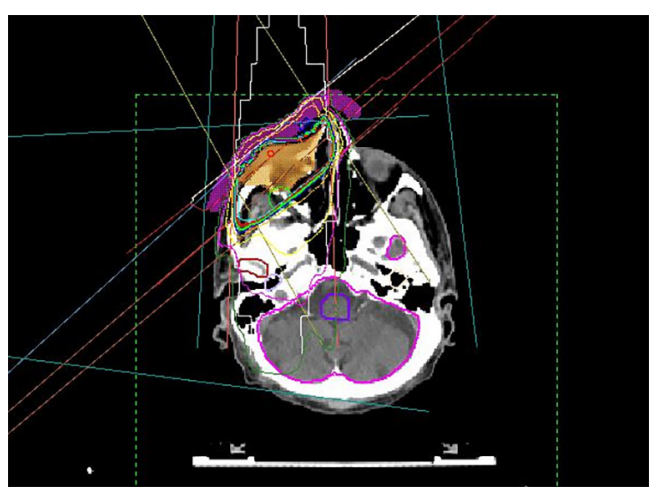

Figure 3 Radiation treatment planning. This picture shows the treatment planning before radiation of periocular BCC with dose distribution and estimation of necessary dose at the risk organs like cornea, lens, optic nerve, and macula. BCC, basal cell carcinoma.

a good dose distribution throughout all skin layers. The irradiation planning therefore encloses the tumor region with an oncological adequate safety margin, usually 0.5 to $1.5 \mathrm{~cm}$. The total dose is chosen between 20 to $77 \mathrm{~Gy}$, depending on the tumor mass $(46,47)$. Figure 3 shows treatment planning for periocular BCC.

A good periorbital radiotherapy planning involves achieving a tumor effective dose at the entire BCC while protecting the radiation-sensitive eye structures such as cornea, lens, retina, N. opticus and tear gland including eyelids with eyelashes $(41,47,48)$. Nevertheless, radiationinduced side effects can occur in different forms. Most often, eyelash loss, sicca symptoms, surface disturbance of the cornea up to conjunctivalization as well as radiationinduced cataracts are observed. Radiation retinopathy and radiation opticopathy are rare in the treatment of BCC and should normally be avoided by good radiation planning $(49,50)$. A collaboration between the ophthalmologist and the radiation therapist helps to design the spatial concept of radiation in such a way that side effects are minimized. Especially in percutaneous irradiation, the motility control of the eye is essential, which is usually achieved by a camera, which the patient fixes with his gaze during the irradiation.

The risk of radiation-related secondary tumor development remains undisputed, with a latency period of at least 10 years, so that the patient's age can be a significant criterion when deciding on radiotherapy $(51,52)$.

\section{Topical treatment}

Topical forms of therapy in BCC are mainly used in dermatology. The use of these alternative forms of therapy is not widely used in ophthalmology. Generally, the patient should initially be offered periorbital micrographically controlled excision. Only in cases when the patient expresses great doubts regarding surgery, these forms of therapy in periorbital BCC are to be offered. Usually then only in cooperation with a specialist experienced in the field. Studies investigating topical treatment especially for periocular BCC are still rare, however some results can already be presented.

\section{Photodynamic therapy}

5-ALA or its ester MAL (most frequently used in Europe) are photosensitizing agents, which are activated with a red-light beam of the wavelength of $635 \mathrm{~nm}$ on the skin. Here, the protoporphyrin IX, which originated in tumor tissue from 5-ALA or MAL, is activated and destroys the tumor cell by means of singlet oxygen formation. With regards to recurrence freedom, ALA photodynamic therapy (ALA-PDT) results in a lower recurrence rate, but at the same time in higher pain scores and more post-treatment side effects (53). Also both forms of PDT are inferior to micrographically controlled surgery as well as to imiquimod therapy (54-56). Side effects-in addition to the pain in treatment-include initial erythema as well as erosion and crust formation a few weeks after treatment (57).

\section{Imiquimod therapy}

Imiquimod therapy is a toll-like receptor 7 and 8 agonist. Initially the treatment spectrum is its use against viruses as a virostatic. Treatment is carried out with a $5 \%$-cream 5 days a week for 6 weeks (58). The European approval for use in BCC includes an indication spectrum of less than 2 $\mathrm{cm}$ tumor diameter. Comparative studies have shown an inferiority to surgery in terms of recurrence freedom, but a superiority to 5-FU therapy as well as PDT with MAL (54-56). Side effects can include redness, swelling, scaling, blistering and pain. Flu-like symptoms with local lymph node swelling can also occur (59).

\section{5-FU}

5-FU is a well-known mitosis inhibitor in ophthalmology, which is currently used in the post-treatment of filamentous glaucoma surgery or for adjuvant treatment of conjunctival neoplasm. It should primarily be considered in patients with low-risk superficial BCC (60). It is applied to the skin in a $5 \%$ concentration 2 times daily for 4 weeks (54). Side effects can also include redness, swelling, scaling, blistering and pain. 


\section{Semi-surgical procedures}

These include the methods of curettage and flat excision, which are more likely to be classified as historical and which should now only rarely be used, and in these cases require close follow-up after therapy. Literature for its use in the periocular region could not yet been found.

\section{Laser therapy}

In the laser treatment of BCC, ablative methods are distinguished from non-ablative methods. In the ablative procedure, superficial skin tumor findings are removed by means of $\mathrm{CO}^{2}$ or Er:YAG lasers. In contrast, in the nonablative procedures, the tumor vessels of BCC are desolate. In a study conducted in 2018 a $\mathrm{CO}_{2}$ laser combined with PDT in the periorbital area showed excellent treatment results for small, inner canthal lesion with no-high risk histopathological subtype (57). For these patients it could be an effective method with minimal complications without major danger of recurrence. However, due to the tendency of BCCs to expand into depth, this treatment option should be considered carefully for high-risk BCC and close followup after treatment is essential.

\section{Electrodessication and curettage (ED\&C)}

ED\&C are usually performed with 3 successive rounds of curettage followed by electrodessication. Woldow et al. performed a study hypothesizing to use the third round of curettage for histological examination in order to predict tumor recurrence. With a follow-up of 2 years, they had a tumor free success rate of $89 \%$. ED\&C with pathological examination in combination with immunohistochemistry had $100 \%$ sensitivity and $70 \%$ specificity at 2 years (61). However, more studies are needed to ensure the safety of this treatment option.

\section{Cryotherapy}

Cryotherapy with liquid nitrogen in contact or spray ingestion leads to icing at $-196{ }^{\circ} \mathrm{C}$. A case series from 1995 for periocular BCC showed a $7.6 \%$ recurrence rate during mean follow-up of 5 years (62). Further comparative studies are needed to confirm these results. Also, scarring usually occurs after cold therapy, which can have the risk to mask recurrence.

\section{Brachytherapy with rhenium-188 paste}

The technique is called dermatological high-doserate beta-brachytherapy (DBBR). It is a Rhenium-188 brachytherapy that is based on a non-sealed beta-emitter that is embedded in a synthetic matrix. The matrix will be applied onto the tumor, protected by a special thin plastic foil that is avoiding all physical contact of the radionuclide directly with the skin. After the calculated required amount of time, the protective foil with the applied radioactive acrylic matrix is removed (63). Usually, one session is sufficient for tumor remission. In rare cases when tumor thickness is too high or recurrence occurs, a second session might be necessary. There are already existing several retrospective studies with promising results. Cipriani et al. presented in the youngest study a $100 \%$ tumor remission after 3 to 12 months for all 52 NMSC patients enrolled in the study (64). Other studies show similar results, with one or two necessary sessions and no side-effects (3). Currently a prospective study is performed in Rostock that looks promising to confirm the prior outcomes. However, there are currently no studies investigating the use of this method for periocular BCC.

\section{Diclofenac}

Due to the possible role of COX2 in the development of BCC, an approach with the COX2 inhibitor diclofenac was pursued. In a Phase II study, an inhibitory effect on superficial BCCs could be seen, while nodular BCCs showed no effect (65). Patients with periocular BCC have not been involved in studies so far. For this reason, treatment with a COX2 inhibitor can currently not be recommended.

\section{Prophylactic substances}

\section{Nicotinamide (Vitamin B3)}

Nicotinamide (Vitamin B3) provides an active ingredient that helps the organism to repair DNA fractures in cells and thus counteract UV damage. Data from the Nurse' Health Study and the Health Professionals Follow Up study, which documented, among other things, nicotinamide intake, were evaluated. The administration of $500 \mathrm{mg}$ nicotinamide twice daily could reduce the formation of BCC in squama carcinoma patients by $20 \%$ (66). However, no prophylactic effect of nicotinamide for BCC development was to be seen as the primary skin tumor (67).

Current studies investigate to role of metabolomics in eyelid BCCs. The results show that Nicotinamide and other metabolites from NAD metabolism have the highest sensitivity, specificity, and prediction accuracy for eyelid BCC. Therefore, metabolites in NAD metabolic pathways could potentially become biomarkers or therapeutic targets in the future (68). 


\section{Retinoid}

In retinoids, a cell cycle inhibitor, in contrast to squamous cell carcinoma, hardly any prophylactic effect was observed. Due to the side effect profile with headache, muscle pain, sicca symptoms, arthralgia, exhaustion, depression, and teratogenicity, current intake is therefore not recommended (69). In addition, the authors refer to the NCNN guidelines for Non-Melanoma Skin Cancers (https://www.nccn.org/).

\section{Conclusions}

Alternative treatment options for periocular BCC are available; however, the use is only indicated when microscopically controlled excision with subsequent oculoplastic reconstruction is not possible. The discussion of each case within an interdisciplinary tumor board is compulsory and also in line with national guidelines.

While the irradiation and the system therapies are aimed at large tumor findings, which should then be discussed in an interdisciplinary tumor conference, the topical procedures are more suitable for small findings without a high risk of recurrence. Due to the lack of therapy success controls for both treatment options, almost all forms of therapy are inferior to micrographically controlled surgery and should therefore only be used if there are substantial reasons against $\mathrm{R} 0$ resection. The prophylaxis of BCC may well be an option in recurrence cases, but is not a must due to the weak data.

It is particularly important to wait for the extent to which adjuvant or neoadjuvant forms of therapy (surgery/system therapy) will be available in the near future, the immune checkpoint inhibitors in the treatment of BCC can continue to assert themselves, and the combination of hedgehog inhibitor and immuno-checkpoint inhibitor can further improve therapy.

\section{Acknowledgments}

Funding: SE is supported by DFG (No. EM 68/13-1), the European Social Fund (No. ESF/14-BM-A55-0001) and the Ministry of Education, Science and Culture of MecklenburgVorpommern, Germany, as well as the Damp Stiftung.

\section{Footnote}

Provenance and Peer Review: This article was commissioned by the editorial office, Frontiers of Oral and Maxillofacial
Medicine for the series "Diagnosis and Treatment of Periorbital Basal Cell Carcinoma". The article has undergone external peer review.

Reporting Checklist: The authors have completed the Narrative Review reporting checklist. Available at https://fomm. amegroups.com/article/view/10.21037/fomm-21-19/rc

Conflicts of Interest: All authors have completed the ICMJE uniform disclosure form (available at https://fomm. amegroups.com/article/view/10.21037/fomm-21-19/coif). The series "Diagnosis and Treatment of Periorbital Basal Cell Carcinoma" was commissioned by the editorial office without any funding or sponsorship. LMH and VK served as the unpaid Guest Editors of the special. LMH serves as an unpaid editorial board member of Frontiers of Oral and Maxillofacial Medicine from September 2020 to August 2022. The authors have no other conflicts of interest to declare.

Ethical Statement: The authors are accountable for all aspects of the work in ensuring that questions related to the accuracy or integrity of any part of the work are appropriately investigated and resolved.

Open Access Statement: This is an Open Access article distributed in accordance with the Creative Commons Attribution-NonCommercial-NoDerivs 4.0 International License (CC BY-NC-ND 4.0), which permits the noncommercial replication and distribution of the article with the strict proviso that no changes or edits are made and the original work is properly cited (including links to both the formal publication through the relevant DOI and the license). See: https://creativecommons.org/licenses/by-nc-nd/4.0/.

\section{References}

1. Fania L, Didona D, Morese R, et al. Basal Cell Carcinoma: From Pathophysiology to Novel Therapeutic Approaches. Biomedicines 2020;8:449.

2. Galindo-Ferreiro A, Sanchez-Tocino H, Diez-Montero C, et al. Characteristics and Recurrence of Primary Eyelid Basal Cell Carcinoma in Central Spain. J Curr Ophthalmol 2020;32:183-8.

3. Sedda AF, Rossi G, Cipriani C, et al. Dermatological high-dose-rate brachytherapy for the treatment of basal and squamous cell carcinoma. Clin Exp Dermatol 2008;33:745-9.

4. Kakkassery V, Emmert S, Adamietz IA, et al. Alternative 
treatment options for periorbital basal cell carcinoma. Ophthalmologe 2020;117:113-23.

5. Skoda AM, Simovic D, Karin V, et al. The role of the Hedgehog signaling pathway in cancer: A comprehensive review. Bosn J Basic Med Sci 2018;18:8-20.

6. Gutzmer R, Solomon JA. Hedgehog Pathway Inhibition for the Treatment of Basal Cell Carcinoma. Target Oncol 2019;14:253-67.

7. Kakkassery V, Loeffler KU, Sand M, et al. Current diagnostics and therapy recommendations for ocular basal cell carcinoma. Ophthalmologe 2017;114:224-36.

8. Sekulic A, Migden MR, Oro AE, et al. Efficacy and safety of vismodegib in advanced basal-cell carcinoma. $\mathrm{N}$ Engl J Med 2012;366:2171-9.

9. Sekulic A, Migden MR, Lewis K, et al. Pivotal ERIVANCE basal cell carcinoma (BCC) study: 12-month update of efficacy and safety of vismodegib in advanced BCC. J Am Acad Dermatol 2015;72:1021-6.e8.

10. Tang JY, Mackay-Wiggan JM, Aszterbaum M, et al. Inhibiting the hedgehog pathway in patients with the basal-cell nevus syndrome. $\mathrm{N}$ Engl J Med 2012;366:2180-8.

11. Basset-Séguin N, Hauschild A, Kunstfeld R, et al. Vismodegib in patients with advanced basal cell carcinoma: Primary analysis of STEVIE, an international, open-label trial. Eur J Cancer 2017;86:334-48.

12. Chen L, Aria AB, Silapunt S, et al. Treatment of advanced basal cell carcinoma with sonidegib: perspective from the 30-month update of the BOLT trial. Future Oncol 2018;14:515-25.

13. Yin VT, Pfeiffer ML, Esmaeli B. Targeted therapy for orbital and periocular basal cell carcinoma and squamous cell carcinoma. Ophthalmic Plast Reconstr Surg 2013;29:87-92.

14. Dummer R, Guminski A, Gutzmer R, et al. The 12-month analysis from Basal Cell Carcinoma Outcomes with LDE225 Treatment (BOLT): A phase II, randomized, double-blind study of sonidegib in patients with advanced basal cell carcinoma. J Am Acad Dermatol 2016;75:113-25.e5.

15. Eiger-Moscovich M, Reich E, Tauber G, et al. Efficacy of Vismodegib for the Treatment of Orbital and Advanced Periocular Basal Cell Carcinoma. Am J Ophthalmol 2019;207:62-70.

16. Su MG, Potts LB, Tsai JH. Treatment of periocular basal cell carcinoma with neoadjuvant vismodegib. Am J Ophthalmol Case Rep 2020;19:100755.

17. Danial C, Sarin KY, Oro AE, et al. An Investigator-
Initiated Open-Label Trial of Sonidegib in Advanced Basal Cell Carcinoma Patients Resistant to Vismodegib. Clin Cancer Res 2016;22:1325-9.

18. Frampton JE, Basset-Séguin N. Vismodegib: A Review in Advanced Basal Cell Carcinoma. Drugs 2018;78:1145-56.

19. Curragh DS, Huilgol SC, Selva D. Neoadjuvant vismodegib in the management of locally advanced periocular basal cell carcinoma. Eye (Lond) 2021;35:2740-5.

20. Ben Ishai M, Tiosano A, Fenig E, et al. Outcomes of Vismodegib for Periocular Locally Advanced Basal Cell Carcinoma From an Open-label Trial. JAMA Ophthalmol 2020;138:749-55.

21. Cox KF, Margo CE. Role of Vismodegib in the Management of Advanced Periocular Basal Cell Carcinoma. Cancer Control 2016;23:133-9.

22. Hou X, Rokohl AC, Ortmann M, et al. Effective treatment of locally advanced periocular basal cell carcinoma with oral hedgehog pathway inhibitor? Graefes Arch Clin Exp Ophthalmol 2020;258:2335-7.

23. Dummer R, Ascierto PA, Basset-Seguin N, et al. Sonidegib and vismodegib in the treatment of patients with locally advanced basal cell carcinoma: a joint expert opinion. J Eur Acad Dermatol Venereol 2020;34:1944-56.

24. Sand M, Bechara FG, Gambichler T, et al. Nextgeneration sequencing of the basal cell carcinoma miRNome and a description of novel microRNA candidates under neoadjuvant vismodegib therapy: an integrative molecular and surgical case study. Ann Oncol 2016;27:332-8.

25. Reck M, Rodríguez-Abreu D, Robinson AG, et al. Pembrolizumab versus Chemotherapy for PD-L1Positive Non-Small-Cell Lung Cancer. N Engl J Med 2016;375:1823-33.

26. Robert C, Schachter J, Long GV, et al. Pembrolizumab versus Ipilimumab in Advanced Melanoma. N Engl J Med 2015;372:2521-32.

27. Weber JS, D'Angelo SP, Minor D, et al. Nivolumab versus chemotherapy in patients with advanced melanoma who progressed after anti-CTLA-4 treatment (CheckMate 037): a randomised, controlled, open-label, phase 3 trial. Lancet Oncol 2015;16:375-84.

28. Sabbatino F, Marra A, Liguori L, et al. Resistance to antiPD-1-based immunotherapy in basal cell carcinoma: a case report and review of the literature. J Immunother Cancer 2018;6:126.

29. Lipson EJ, Lilo MT, Ogurtsova A, et al. Basal cell carcinoma: PD-L1/PD-1 checkpoint expression and tumor 
regression after PD-1 blockade. J Immunother Cancer 2017;5:23.

30. Fischer S, Hasan Ali O, Jochum W, et al. Anti-PD-1 Therapy Leads to Near-Complete Remission in a Patient with Metastatic Basal Cell Carcinoma. Oncol Res Treat 2018;41:391-4.

31. Falchook GS, Leidner R, Stankevich E, et al. Responses of metastatic basal cell and cutaneous squamous cell carcinomas to anti-PD1 monoclonal antibody REGN2810. J Immunother Cancer 2016;4:70.

32. Cannon JGD, Russell JS, Kim J, et al. A case of metastatic basal cell carcinoma treated with continuous PD-1 inhibitor exposure even after subsequent initiation of radiotherapy and surgery. JAAD Case Rep 2018;4:248-50.

33. Bourke MG, Salwa SP, Sadadcharam M, et al. Effective treatment of intractable cutaneous metastases of breast cancer with electrochemotherapy: Ten-year audit of single centre experience. Breast Cancer Res Treat 2017;161:289-97.

34. Kreuter A, van Eijk T, Lehmann P, et al. Electrochemotherapy in advanced skin tumors and cutaneous metastases - a retrospective multicenter analysis. J Dtsch Dermatol Ges 2015;13:308-15.

35. Campana LG, Testori A, Curatolo P, et al. Treatment efficacy with electrochemotherapy: A multi-institutional prospective observational study on 376 patients with superficial tumors. Eur J Surg Oncol 2016;42:1914-23.

36. Reinhold U. Electrochemotherapy for primary skin cancer and skin metastasis related to other malignancies. Anticancer Drugs 2011;22:711-8.

37. Kis E, Baltás E, Kinyó A, et al. Successful treatment of multiple basaliomas with bleomycin-based electrochemotherapy: a case series of three patients with Gorlin-Goltz syndrome. Acta Derm Venereol 2012;92:648-51.

38. Strom T, Harrison LB. Radiotherapy for management of basal and squamous cell carcinoma. Curr Probl Cancer 2015;39:237-47.

39. Swanson EL, Amdur RJ, Mendenhall WM, et al. Radiotherapy for basal cell carcinoma of the medial canthus region. Laryngoscope 2009;119:2366-8.

40. Krema H, Herrmann E, Albert-Green A, et al. Orthovoltage radiotherapy in the management of medial canthal basal cell carcinoma. Br J Ophthalmol 2013;97:730-4.

41. Hauschild A, Breuninger H, Kaufmann R, et al. Brief S2k guidelines--Basal cell carcinoma of the skin. J Dtsch Dermatol Ges 2013 ;11 Suppl 3:10-5, 11-6.
42. Duinkerken CW, Lohuis PJFM, Crijns MB, et al. Orthovoltage $\mathrm{X}$-rays for Postoperative Treatment of Resected Basal Cell Carcinoma in the Head and Neck Area. J Cutan Med Surg 2017;21:243-9.

43. Rishi A, Hui Huang S, O'Sullivan B, et al. Outcome following radiotherapy for head and neck basal cell carcinoma with 'aggressive' features. Oral Oncol 2017;72:157-64.

44. Ballester-Sánchez R, Pons-Llanas O, Candela-Juan C, et al. Efficacy and safety of electronic brachytherapy for superficial and nodular basal cell carcinoma. J Contemp Brachytherapy 2015;7:231-8.

45. Rio E, Bardet E, Ferron C, et al. Interstitial brachytherapy of periorificial skin carcinomas of the face: a retrospective study of 97 cases. Int J Radiat Oncol Biol Phys 2005;63:753-7.

46. Delishaj D, Rembielak A, Manfredi B, et al. Nonmelanoma skin cancer treated with high-dose-rate brachytherapy: a review of literature. J Contemp Brachytherapy 2016;8:533-40.

47. Cho M, Gordon L, Rembielak A, et al. Utility of radiotherapy for treatment of basal cell carcinoma: a review. Br J Dermatol 2014;171:968-73.

48. Berking C, Hauschild A, Kölbl O, et al. Basal cell carcinoma-treatments for the commonest skin cancer. Dtsch Arztebl Int 2014;111:389-95.

49. Emami B, Lyman J, Brown A, et al. Tolerance of normal tissue to therapeutic irradiation. Int J Radiat Oncol Biol Phys 1991;21:109-22.

50. Marks LB, Yorke ED, Jackson A, et al. Use of normal tissue complication probability models in the clinic. Int J Radiat Oncol Biol Phys 2010;76:S10-9.

51. McKeown SR, Hatfield P, Prestwich RJ, et al. Radiotherapy for benign disease; assessing the risk of radiation-induced cancer following exposure to intermediate dose radiation. Br J Radiol 2015;88:20150405.

52. Taylor RE, Hatfield P, McKeown SR, et al. Radiotherapy for Benign Disease: Current Evidence, Benefits and Risks. Clin Oncol (R Coll Radiol) 2015;27:433-5.

53. Kessels JPHM, Kreukels H, Nelemans PJ, et al. Treatment of superficial basal cell carcinoma by topical photodynamic therapy with fractionated 5 -aminolaevulinic acid $20 \%$ vs. two-stage topical methyl aminolaevulinate: results of a randomized controlled trial. Br J Dermatol 2018;178:1056-63.

54. Love WE, Bernhard JD, Bordeaux JS. Topical imiquimod or fluorouracil therapy for basal and squamous cell carcinoma: a systematic review. Arch Dermatol 
2009;145:1431-8.

55. Bath-Hextall F, Ozolins M, Armstrong SJ, et al. Surgical excision versus imiquimod $5 \%$ cream for nodular and superficial basal-cell carcinoma (SINS): a multicentre, non-inferiority, randomised controlled trial. Lancet Oncol 2014;15:96-105.

56. Williams HC, Bath-Hextall F, Ozolins M, et al. Surgery Versus 5\% Imiquimod for Nodular and Superficial Basal Cell Carcinoma: 5-Year Results of the SINS Randomized Controlled Trial. J Invest Dermatol 2017;137:614-9.

57. Mercuri SR, Brianti P, Dattola A, et al. CO2 laser and photodynamic therapy: Study of efficacy in periocular BCC. Dermatol Ther 2018;31:e12616.

58. Carneiro RC, de Macedo EM, Matayoshi S. Imiquimod $5 \%$ cream for the treatment of periocular Basal cell carcinoma. Ophthalmic Plast Reconstr Surg 2010;26:100-2.

59. Geisse J, Caro I, Lindholm J, et al. Imiquimod 5\% cream for the treatment of superficial basal cell carcinoma: results from two phase III, randomized, vehicle-controlled studies. J Am Acad Dermatol 2004;50:722-33.

60. Peris K, Fargnoli MC, Garbe C, et al. Diagnosis and treatment of basal cell carcinoma: European consensusbased interdisciplinary guidelines. Eur J Cancer 2019;118:10-34.

61. Woldow AB, Melvin ME. Early Detection of Desiccation and Curettage Failure in the Treatment of Basal Cell Carcinoma. Dermatology 2016;232:696-9.

62. Tuppurainen K. Cryotherapy for eyelid and periocular

doi: 10.21037/fomm-21-19

Cite this article as: Erikson K, Brosig A, Zimbelmann MW, Emmert S, Guo Y, Heindl LM, Adamietz IA, Ranjbar M, Grisanti S, Kakkassery V. Alternative treatment options for periocular basal cell carcinoma: a narrative review. Front Oral Maxillofac Med 2022;4:25. basal cell carcinomas: outcome in 166 cases over an 8-year period. Graefes Arch Clin Exp Ophthalmol 1995;233:205-8.

63. Carrozzo AM, Sedda AF, Muscardin L, et al. Dermo beta brachytherapy with 188-Re in squamous cell carcinoma of the penis: a new therapy. Eur J Dermatol 2013;23:183-8.

64. Cipriani C, Desantis M, Dahlhoff G, et al. Personalized irradiation therapy for NMSC by rhenium-188 skin cancer therapy: a long-term retrospective study. J Dermatolog Treat 2022;33:969-75.

65. Brinkhuizen T, Frencken KJ, Nelemans PJ, et al. The effect of topical diclofenac $3 \%$ and calcitriol $3 \mu \mathrm{g} / \mathrm{g}$ on superficial basal cell carcinoma (sBCC) and nodular basal cell carcinoma (nBCC): A phase II, randomized controlled trial. J Am Acad Dermatol 2016;75:126-34.

66. Chen AC, Martin AJ, Choy B, et al. A Phase 3 Randomized Trial of Nicotinamide for Skin-Cancer Chemoprevention. N Engl J Med 2015;373:1618-26.

67. Park SM, Li T, Wu S, et al. Niacin intake and risk of skin cancer in US women and men. Int J Cancer 2017;140:2023-31.

68. Huang J, Schaefer J, Wang Y, et al. Metabolic signature of eyelid basal cell carcinoma. Exp Eye Res 2020;198:108140.

69. Kadakia KC, Barton DL, Loprinzi CL, et al. Randomized controlled trial of acitretin versus placebo in patients at high-risk for basal cell or squamous cell carcinoma of the skin (North Central Cancer Treatment Group Study 969251). Cancer 2012;118:2128-37. 